\title{
Biological properties of adriamycin bound to biodegradable polymeric carriers
}

\author{
C.J.T. Hoes ${ }^{a}$, J. Grootoonk ${ }^{a}$, R. Duncan ${ }^{\text {, }}$, I.C. Hume ${ }^{\text {b }}$, M. Bhakoo ${ }^{\text {b J.M.W. Bouma }}{ }^{\text {c }}$ \\ and J. Feijen \\ "Department of Chemical Technology, University of Twente, Enschede, Netherlands; ${ }^{b}$ Department of Biological Sciences, \\ University of Keele, Keele, UK; ${ }^{\circ}$ Department of Biochemistry, University of Groningen, Groningen, Netherlands
}

(Received 11 May 1992; accepted in revised form 3 August 1992)

Three different conjugates having adriamycin (ADR) bound to the side chain carboxyl groups of high-molecular weight poly ( $\alpha$-L-glutamic acid) (PGA) either directly or by interpolation of GlyGly and GlyGlyGlyLeu spacers, respectively, were compared with respect to immunogenicity and cytotoxicity in mice as well as release of drug by lysosomal enzymes. The cytotoxic efficacy of a single i.p. dose of each conjugate ( $5 \mathrm{mg}$ ADR-equiv./kg) against L1210 leukemia cells implanted i.p. in $\mathrm{DBA}_{2}$ mice was studied by monitoring the survival time, the body weight and the number of long-term survivors (LTS). PGA-GlyGlyGlyLeu-ADR and PGA-GlyGly-ADR significantly enhanced the mean survival time (MST) of treated animals compared with the untreated control group (T/C 148-149\%) as did free ADR (T/C 147\%). The tetrapeptide-spacer containing conjugate effected the presence of LTS at day $50(2 / 5)$ as did free ADR (1/5).

The secondary antibody response of the drug conjugates elicited in $\mathrm{A} / \mathrm{J}$ mice after repeated dosage $(125 \mu \mathrm{g} / \mathrm{mouse})$ at day 0,14 and 28 was evaluated at day 35 using the ELISA technique. IgG titers varied from a very low value (PGA-GlyGlyGlyLeu-ADR) to moderately high levels (PGA-ADR, PGAGlyGly-ADR) which are 2-3 orders of magnitude below that obtained for the strong immunogen bovine IgG. The data suggest that certain parts on the surface of the conjugates are immunogenic.

The release of extractable low-molecular weight products from the conjugates mediated by lysosomal enzymes was analyzed using reversed-phase HPLC. The release profile of ADR as well as Gly-ADR, Leu-ADR or GlyLeu-ADR was determined. The total amount of ADR released after $77 \mathrm{~h}$ was $3.6 \%$ for PGA-GlyGlyGly-Leu-ADR, $1.0 \%$ for PGA-GlyGly-ADR and $0.5 \%$ for PGA-ADR. With all conjugates unidentified products were produced.

It is proposed that the mechanism of action of the polymeric conjugates under in vivo conditions may be due to pinocytic capture followed by lysosomal degradation with release of ADR.

Key words: Adriamycin; Poly ( $\alpha$-L-glutamic acid); Cytostatics; Polymeric drug; Immunogenicity; Cytotoxicity

Correspondence to: J. Feijen, Dept. of Chemical Technology, University of Twente, P.O. Box 217, 7500 AE Netherlands. 


\section{Introduction}

Delivery of cytostatic agents with the aid of soluble polymeric drug conjugates is a strategy to improve chemotherapy [1]. The pharmacokinetics and biodistribution of polymer-bound drugs will be different from those of the free drug. Generally, drug conjugates having molecular weights above the renal excretion limit may reside in the body for prolonged periods. The release of drug depends critically on the design of the drug-polymer bond. This bond can be adapted to be sensitive to slow hydrolytic cleavage in the circulation yielding an approximately constant level of free drug for a prolonged period thereby suppressing drug-mediated toxic side effects. Alternatively, macromolecular drug conjugates are taken up by cells by the process of pinocytosis and drug release is occurring intracellularly due to the acidic environment in endosomal particles or the action of lysosomal enzymes. To enhance specifically the intracellular degradation of the drug-polymer bond acid-sensitive linkers or lysosomally cleavable peptide spacers are used to link the drug with the carrier [1]. Notably, the in vitro and in vivo biological properties in animals of conjugates of poly [ (2hydroxypropyl)methacrylamide ], polyHPMA, and cytostatic agents have been studied by one of us (R.D.) extensively, including immunogenicity, biocompatibility, pharmacokinetics, biodistribution, pinocytosis, drug release by intracellular enzymes and cytotoxic effectivity $[2,3]$.

The cytostatic drug adriamycin (ADR) is used intensively in the treatment of various tumors [4]. Its main side effects are dose-limiting cardiotoxicity and myelosuppression [4]. A major aim of delivering ADR with polymeric systems is to reduce the side effects of the drug by preventing peak concentrations of drug in the circulation and by effecting a selective delivery towards tumor cells. In previous papers we described the synthesis and in vitro properties of conjugates of ADR and biodegradable polymeric carriers derived from poly ( $\alpha$-L-glutamic acid) (PGA) [5-7]. PGA is biodegradable, non-immunogenic and non-toxic $[8,9]$ and it allows the binding of drug via enzymatically or hydrolytically labile bonds [1,10-12]. Recently, we described the synthesis and biodistribution in mice of immunoconjugates of the human monoclonal antibody IgM 16.88 and the polymeric drug carriers PGA and poly [ $N^{5}$-(2-hydroxyethyl)-L-glutamine], PHEG [13]. This study indicates the suitability of polyanionic PGA as well as uncharged PHEG for use as the drug carrier in immunoconjugates. The ADR conjugates described previously [5-7] are designed to yield release of drug after pinocytic uptake by cells followed by lysosomal cleavage of the drug-polymer bond by using appropriate peptide spacers between carrier and drug but were not studied in vivo.

The main purpose of the present paper is the study of immunogenicity and cytotoxicity against L12 10 leukemia cells in mice of PGA-derived ADR conjugates with different spacers between drug and carrier. The release of drug effected by lysosomal enzymes is described to allow correlation of biodegradability with in vivo cytotoxicity. The synthesis of new polymeric conjugates and of amino acid and peptide derivatives of ADR is described.

\section{Abbreviations}

ADR, adriamycin; BSA, bovine serum albumin; CDI, $N, N^{\prime}$-carbonyldiimidazole; CFA, complete Freund's adjuvant; d, doublet; dd, double doublet; DCCI, $N, N^{\prime}$-dicyclohexylcarbodiimide; $\mathrm{DMF}, \quad N, N$-dimethylformamide; DMSO, dimethylsulfoxide; DNM, daunomycin; $\mathrm{DP}_{\mathrm{n}}$, number-average degree of polymerization; $\mathrm{DP}_{\mathrm{w}}$, weight-average degree of polymerization; EDTA, ethylene diamine tetraacetate; EEDQ, $N$ ethoxycarbonyl-2-ethoxy-1,2-dihydroquinoline; ELISA, enzyme-linked immunoassay; GlyGly$\mathrm{OBu}^{\mathrm{t}}$, glycylglycine tert-butyl ester; Gly-OBu${ }^{\mathrm{t}}$, glycine tert-butyl ester; GSH, glutathione (reduced ); HOAc, acetic acid; HONSu, $N$-hydrox- 
ysuccinimide; HOBT, 1-hydroxybenzotriazole; HPMA, $N$-(2-hydroxypropyl)methacrylamide; HP-SEC, high-performance size exclusion chromatography; LALLS, low-angle laser light scattering; LTS, long-term survivors; m, multiplet; $M_{\mathrm{n}}$, number-average molecular weight; $M_{\mathrm{w}}$, weight-average molecular weight; MSA, methanesulphonic acid; MST, mean survival time; NCA, $N$-carboxyanhydride; $\mathrm{Nh}$, ninhydrin; PBLG, poly ( $\gamma$-benzyl-L-glutamate); PBS, phosphate-buffered saline; PGA, poly $(\alpha$-L-glutamate); PHEG, poly [ $N^{5}$-(2-hydroxyethyl)-Lglutamine 1; PLG, $\gamma$-piperonyl-L-glutamate; PLG NCA, $\gamma$-piperonyl-L-glutamate $N$-carboxyanhydride; PPLG, poly [ $(\gamma$-piperonyl) $\alpha$-L-glutamate ]; RH, spray reagent for detection of peptide bonds in TLC; s, singlet; SD, standard deviation; SE, standard error; SEC, size exclusion chromatography; THF, tetrahydrofuran; TFA, trifluoroacetic acid; TLC, thin-layer chromatography; TMG, $N, N, N^{\prime}, N^{\prime}$-tetramethylguanidine; Trt, triphenylmethyl; Trt-Gly, $N$-triphenylmethylglycine; Trt-Gly-ONSu, $\quad N$ triphenylmethylglycine succinimidyl ester; TrtLeu-OBT, $N$-triphenylmethylglycine 1-hydroxybenzotriazole ester; Z-Gly, $N$-benzyloxycarbonylglycine.

\section{Materials and Methods}

\section{Materials}

Tetrahydrofuran (THF) and dioxane were refluxed overnight and distilled in the presence of sodium wire and benzophenone as an indicator. This procedure was repeated until development of a dark-blue color, indicating the absence of water. DMF was distilled in vacuo and used immediately. $N$-ethylmorpholine and triethylamine were distilled from $\mathrm{KOH}$. Trifluoroacetic acid (TFA) was distilled.

The following compounds were obtained from the manufacturer indicated and were used as supplied. $\quad N^{\alpha}$-benzoyl-Phe-Val-Arg-p-nitroanilide, Serva, FRG; $N$-ethoxycarbonyl-2-ethoxy1,2-dihydroquinoline (EEDQ), Serva, FRG; GlyLeu, Sigma, USA; GlyGlyLeu, Sigma, USA; glycine tert-butyl ester (Gly-OBu ${ }^{t}$ ), Serva, FRG; $N$-hydroxysuccinimide (HONSu), Janssen, Belgium; 1-hydroxybenzotriazole (HOBT), Sigma, USA; $N$-benzyloxycarbonylglycine (Z-Gly), Sigma, USA.

The following compounds were prepared as described. Glycylglycine tert-butyl ester hydrochloride (HCl.GlyGly-OBu ${ }^{\mathfrak{t}}$ ) [14]; PGA-ADR [5]; PGA-GlyGlyGlyLeu as described for PGAGlyGlyLeu [5]; PGA-GlyGlyGlyLeu-ADR as described for PGA-GlyGlyLeu-ADR [5]; $\gamma$-piperonyl-L-glutamate (PLG) [15]; $\gamma$-piperonyl-Lglutamate $N$-carboxyanhydride (PLG NCA) [16]; $N$-triphenylmethylglycine succinimidyl ester (Trt-Gly-ONSu) [17]; $N$-triphenylmethylglycine 1-hydroxybenzotriazole ester (TrtLeu-OBT) [18].

Tritosomes were isolated from rat liver by a modification of the method of Trouet [19] as described by Kussendrager et al. [20]. The tritosomes $(0.52 \mathrm{mg} / \mathrm{ml}$ of protein $)$ were about 70 fold purified in respect to the liver homogenate as determined by measuring the specific activity of acid phosphatase.

\section{Methods}

\section{Analytical procedures}

${ }^{1} \mathrm{H}$-NMR spectra were recorded on a Bruker WP $80(80 \mathrm{MHz})$, a Nicolet $1280(200 \mathrm{MHz})$ or a Bruker AC $250(250 \mathrm{MHz})$. Chemical shifts $(\delta)$ are given in ppm relative to tetramethylsilane; theoretical values of the number of protons of each signal are given between brackets. Thinlayer chromatography (TLC) was performed on silica coated on plastic sheets $\mathrm{GF}_{254}$ (Merck, FRG) using the following solvent systems: A, chloroform/methanol $(95 / 5 ; \mathrm{v} / \mathrm{v})$; B, chloroform/methanol $(9 / 1 ; \mathrm{v} / \mathrm{v})$; C, chloroform/ methanol $(8 / 2 ; \mathrm{v} / \mathrm{v}) ; \mathrm{D}$, chloroform/methanol/acetic acid $(85 / 10 / 5 ; \mathrm{v} / \mathrm{v}) ; \mathrm{E}, n$-butanol/ acetic acid/water $(4 / 1 / 1 ; v / v)$. Spots were visualized under UV-light, by spraying with Nh solution (Merck, FRG) followed by heating for 5$10 \mathrm{~min}$ at $110^{\circ} \mathrm{C}$ for detection of amino groups, or by spraying with $o$-tolidine/KI (RH reagent) [21] after chlorination for the detection of peptide bonds. 
ADR concentrations were calculated from the absorbance at $490 \mathrm{~nm}$ using a molar absorbance coefficient of $8500 \mathrm{M}^{-1} \mathrm{~cm}^{-1}$.

$\mathrm{ADR}$ and ADR-related extractable products from the degradation studies of ADR conjugates were analyzed by HPLC using a Lichrospher 100 RP8 column $(125 \times 4 \mathrm{~mm}$; $5 \mu \mathrm{m}$ particle size) (Merck, FRG). The eluent was prepared by mixing water, acidified to $\mathrm{pH} 2.25$ with perchloric acid, and acetonitrile $(70 / 30 ; \mathrm{v} / \mathrm{v})$. A flow rate of $1 \mathrm{ml} / \mathrm{min}$ was used. The fluorescence of the column eluate was monitored at 560 $\mathrm{nm}\left(\lambda_{\mathrm{exc}} 488 \mathrm{~nm}\right)$ with a Perkin-Elmer LS-3 spectrometer equipped with a HPLC flow cell. Elution profiles were assigned to ADR or its amino acid/peptide derivatives by spiking and by comparison of retention times. The amounts of $A D R$ or assigned ADR derivatives were determined from the peak height and extraction efficiency using a calibration curve. The retention of ADR or derivatives is expressed as $k^{\prime}$ defined as $t_{\mathrm{r}}-t_{0} / t_{0}$ in which $t_{\mathrm{r}}$ is the elution time of the compound of interest and $t_{0}$ is the elution time of unretarded compounds.

\section{Characterization of polymers}

Average molecular weights of poly [ ( $\gamma$-piperonyl)- $\alpha$-L-glutamate] (PPLG) $\left(M_{\mathrm{w}}, M_{\mathrm{n}}\right)$ were determined by high-performance size-exclusion (HP-SEC)/low angle laser light scattering (LALLS) analysis using DMF as the eluent at a flow rate of $1.0 \mathrm{ml} / \mathrm{min}$. The HP-SEC unit, consisting of a Waters model $6000 \mathrm{~A}$ pump and a Waters U6K injector, was connected to three Waters $\mu$ Styragel $\left(10^{5}, 10^{4}, 10^{3} \AA\right)$ HPLC columns $(7.8 \times 300 \mathrm{~mm})$ in series. The column eluate was monitored by a Chromatix KMX-6 LALLS apparatus and a Waters R 401 differential refractometer. Refractive index increments $(\mathrm{d} n / \mathrm{d} c)$ at $633 \mathrm{~nm}$ were determined using a modified Brice-Phoenix BP-2000-V differential refractometer. The $\mathrm{d} n / \mathrm{d} c$ value of PPLG was $0.110 \mathrm{ml} / \mathrm{g}$.

The average molecular weight of PGA $\left(M_{\mathrm{w}}\right)$ was determined by intrinsic viscosity measurements in $0.19 \mathrm{M} \mathrm{NaCl}, 10 \mathrm{mM}$ sodium phosphate, $\mathrm{pH} 7.3$, using an Ubbelohde capillary di- lution viscometer or capillary micro-viscometer at $25^{\circ} \mathrm{C}$. The PGA molecular weight was calculated from the intrinsic viscosity $[\eta]$ and the relation $[\eta]=4.1 \times 10^{-5} \times\left[M_{\mathrm{w}}\right]^{0.94}[22]$.

The amount of piperonyl ester groups in PGA was determined from the UV spectra of solutions of PGA sodium salt in water using a molar absorbance coefficient of $3300 \mathrm{M}^{-1} \cdot \mathrm{cm}^{-1}$ at 290 $\mathrm{nm}[16]$.

\section{Synthetic procedures}

\section{Trt-GlyGlyLeu}

$N$-Ethylmorpholine $(0.19 \mathrm{ml}, 1.49 \mathrm{mmol})$ and Trt-Gly-ONSu (690 mg, $1.67 \mathrm{mmol})$ were added to a suspension of GlyLeu $(280.3 \mathrm{mg}, 1.49$ $\mathrm{mmol})$ in DMF $(4.0 \mathrm{ml})$. The mixture was stirred for $6 \mathrm{~h}$ at room temperature, TLC (solvent B) indicating complete conversion. Water $(40 \mathrm{ml})$ was added and the $\mathrm{pH}$ was adjusted to 8.5 with $7 \% \mathrm{NaHCO}_{3}$. The solution was extracted with ethyl acetate $(4 \times 20 \mathrm{ml})$ and the aqueous layer was acidified to $\mathrm{pH} 2.5$ with $1 \mathrm{~N}$ $\mathrm{KHSO}_{4}$. The mixture was extracted with ethyl acetate $(4 \times 25 \mathrm{ml})$, the combined extracts were washed with water $(4 \times 8 \mathrm{ml})$, dried with $\mathrm{Na}_{2} \mathrm{SO}_{4}$ and evaporated to dryness in vacuo. A solution of the remaining oil in ethyl acetate $(11 \mathrm{ml})$ was slowly added with stirring to hexanes (mixed isomers, $70 \mathrm{ml}$ ). The precipitate was isolated by filtration, washed with hexanes and dried in vacuo. Yield $547 \mathrm{mg}(75 \%)$ of Trt-GlyGlyLeu, homogeneous on TLC (solvents $B, C ; N h, R H$ ). ${ }^{1} \mathrm{H}-\mathrm{NMR}$ (DMSO-d $\mathrm{d}_{6}$ ), consistent with the proposed structure: $\delta 0.88$, d, $6.0(6) \mathrm{H}$, Leu $\delta-\mathrm{CH}_{3}$; $\delta 1.57, \mathrm{~m}, 2.9$ (3) $\mathrm{H}$, Leu $\gamma-\mathrm{CH}$ and Leu $\beta-\mathrm{CH}_{2}$; $\delta 2.69, \mathrm{~s}, 2.3(2) \mathrm{H}, \mathrm{Gly}-2 \mathrm{CH}_{2} ; \delta 3.80, \mathrm{~d}, 2.3(2)$ $\mathrm{H}$, Gly-1 $\mathrm{CH}_{2} ; \delta 4.26, \mathrm{~m}, 1.2(1) \mathrm{H}$, Leu $\alpha-\mathrm{CH}$; $\delta 7.34, \mathrm{~m}, 14(15) \mathrm{H}$, trityl $\mathrm{C}_{6} \mathrm{H}_{5} ; \delta 8.05, \mathrm{~d}, 1.0$ (1) $\mathrm{H}$, Leu NHCO; $\delta 8.26, \mathrm{t}, 0.8$ (1) $\mathrm{H}$, Gly-2 NHCO.

\section{GlyGlyGlyLeu}

$N$-Ethylmorpholine $(0.93 \mathrm{ml}, 7.3 \mathrm{mmol})$ and Trt-Gly-ONSu ( $3.04 \mathrm{~g}, 7.3 \mathrm{mmol})$ were added to a suspension of GlyGlyLeu (1.82 g, peptide content $85 \%, 6.3 \mathrm{mmol})$ in DMF $(18 \mathrm{ml})$. The 
mixture was stirred for 3 days at room temperature and TLC indicating complete conversion. Water $(100 \mathrm{ml})$ was added and the $\mathrm{pH}$ was adjusted to 8.5 with $1 \mathrm{~N} \mathrm{NaOH}$. The solution was filtered and the clear filtrate was acidified to $\mathrm{pH}$ 2.5 with $1 \mathrm{~N} \mathrm{KHSO}_{4}$. The mixture was extracted with chloroform $/$ methanol $9 / 1 \mathrm{v} / \mathrm{v}(300 \mathrm{ml}$; $3 \times 100 \mathrm{ml}$ ), the combined extracts were washed with water $(4 \times 50 \mathrm{ml})$ and were evaporated to dryness in vacuo. The residue was repeatedly evaporated to dryness in vacuo after addition of methanol. A solution of the remaining oil in ethyl acetate $(50 \mathrm{ml})$ was slowly added with stirring to hexane (mixed isomers, $500 \mathrm{ml}$ ) and stirring was continued for $15 \mathrm{~h}$. The precipitate was isolated by filtration and dried in vacuo. Yield 3.56 $\mathrm{g}$ of Trt-GlyGlyGlyLeu, practically homogeneous on TLC (solvents B, C; Nh, RH) showing trace amounts of Trt-Gly. A solution of the product $(2.2 \mathrm{~g})$ in $75 \%$ acetic acid $(30 \mathrm{ml})$ was stirred for $3 \mathrm{~h}$ at room temperature. Water $(120 \mathrm{ml})$ was added and the solution was filtered. The clear filtrate was evaporated to dryness in vacuo and the residue was repeatedly evaporated to dryness in vacuo after addition of methanol $(2 \times 50 \mathrm{ml})$ and toluene $(4 \times 50 \mathrm{ml})$. A solution of the product in water ( $50 \mathrm{ml})$ was filtered $(0.2 \mu \mathrm{m})$ and was lyophilized. Yield $938 \mathrm{mg}$ of GlyGlyGlyLeu (peptide content $85 \%$, $68 \%$ relative to GlyGlyLeu ). Practically homogeneous on TLC (solvents D, E; $\mathrm{Nh}, \mathrm{RH}$ ) showing trace amounts of Gly. ${ }^{1} \mathrm{H}$ NMR (DMSO- $\mathrm{d}_{6}, \delta$ in ppm relative to tetramethylsilane) consistent with the proposed structure: $\delta 0.83, \mathrm{~d}, 5.9(6) \mathrm{H}$, Leu $\delta-\mathrm{CH}_{3} ; \delta 1.48, \mathrm{~m}$, 3.2 (3) $\mathrm{H}$, Leu $\gamma-\mathrm{CH}$ and $\beta-\mathrm{CH}_{2} ; \delta 3.41$, s (broad), 2.1 (2) $\mathrm{H}$ and 3.73, s (broad), 4.2 (4) $\mathrm{H}$, various Gly $\mathrm{CH}_{2} ; \delta 4.1, \mathrm{~m}, 1$ (1) $\mathrm{H}$, Leu $\alpha$ $\mathrm{CH} ; \delta 7.50, \mathrm{~d}, 1.0$ (1) H, Leu NH; $\delta 8.33, \mathrm{t}, 1.0$ (1) H, Gly NH; $\delta 8.73$, s (very broad), 0.7 (1) $\mathrm{H}$, Gly NH; the signal from the ammonium group was not observed probably due to fast exchange with HOD. The signals at $\delta 7.50,8.33$ and 8.73 disappear after addition to $\mathrm{D}_{2} \mathrm{O}$ confirming the exchangeability of the protons. Amino acid analysis after acidic hydrolysis: Gly, 2.97; Leu, 1.04.

\section{LeU-ADR}

Trt-Leu-OBT (92.9 mg, $0.190 \mathrm{mmol})$ was added to a stirred suspension of ADR (hydrochloride) $(99.9 \mathrm{mg}, 0.172 \mathrm{mmol})$ in DMF (3.0 $\mathrm{ml})$ containing $N$-ethylmorpholine (43.8 $\mu \mathrm{l}$, $0.344 \mathrm{mmol}$ ). The mixture was stirred for $23 \mathrm{~h}$ at room temperature, TLC (solvent $\mathrm{A}$ ) indicating complete conversion, and the clear solution was evaporated to dryness in vacuo. The residue was extracted twice with toluene/hexane $1 / 2$ $\mathrm{v} / \mathrm{v}(3 \mathrm{ml})$, the extract was discarded and the residue evaporated to dryness in vacuo. The residue was purified by chromatography on a column of silicagel $(16 \times 2.6 \mathrm{~cm}$; particle size $40-$ $63 \mu \mathrm{m}$ ) with chloroform $/$ methanol $95 / 5 \mathrm{v} / \mathrm{v}$ as the eluent. Fractions containing the major product were pooled and evaporated to dryness yielding Trt-Leu-ADR (102 mg, 65\%). The product was mixed with $75 \%$ acetic acid and stirred for $2.5 \mathrm{~h}$ at room temperature, TLC (solvents D, E) indicating complete deblocking. Water $(13 \mathrm{ml})$ was added and the precipitate was removed by filtration (Whatman GF/A). The $\mathrm{pH}$ of the filtrate was adjusted to 8.5 with $1 \mathrm{~N}$ and $0.1 \mathrm{~N}$ $\mathrm{NaOH}$ with vigorous stirring and the mixture was extracted with chloroform/methanol $4 / 1 \mathrm{v} / \mathrm{v}$ $(4 \times 50 \mathrm{ml})$. The combined organic extracts were evaporated to dryness in vacuo. Water $(20 \mathrm{ml})$ was added and the vigorously stirred mixture was acidified to $\mathrm{pH} 3.5$ with $0.1 \mathrm{~N} \mathrm{HCl}$. The solution was filtered $(0.45 \mu \mathrm{m})$ and lyophilized yielding Leu-ADR (hydrochloride) (58.3 $\mathrm{mg}, 49 \%$ ). Homogeneous on TLC (solvents D, E). M.p. $175-178^{\circ} \mathrm{C}$ (dec.) $\left(193^{\circ} \mathrm{C}\right.$, (dec.) [23]. ${ }^{1} \mathrm{H}$ NMR (DMSO- $\mathrm{d}_{6}$ ) consistent with proposed structure; characteristic signals: $\delta 0.89$, dd, 5.7 (6) $\mathrm{H}$, Leu $\delta \mathrm{CH}_{3} ; \delta 1.13$, d, 3.0 (3) H, ADR $\mathrm{CH}_{3}-\mathrm{C}_{5} ; \delta 1.53, \mathrm{~m}, 3.3$ (3) $\mathrm{H}$, Leu $\beta-\mathrm{CH}_{2}$ and $\mu$ $\mathrm{CH} ; \delta 3.99$, s, 3.0 (3) H, ADR $\mathrm{CH}_{3} \mathrm{O}-\mathrm{C}_{4} ; \delta 8.10$, s (broad), 2.0 (3) H, Leu $\mathrm{NH}_{3} ; \delta 8.33, \mathrm{~d}, 1.1$ (1) H, ADR NHCO.

Gly-ADR

Gly-ADR (hydrochloride) was prepared by reaction of Trt-Gly-ONSu and ADR according to the procedure described for Leu-ADR. Yield 
$39 \%$, homogeneous on TLC (solvents D, E). ${ }^{1} \mathrm{H}-$ NMR (DMSO-d ${ }_{6}$ ) consistent with the proposed structure; characteristic signals: $\delta 1.17, \mathrm{~d}, 2.9$ (3) $\mathrm{H}, \mathrm{ADR} \mathrm{CH}_{3}-\mathrm{C}_{5} ; \delta 4.00, \mathrm{~s}, 3.1$ (3) $\mathrm{H}, \mathrm{ADR}$ $\mathrm{CH}_{3} \mathrm{O}-\mathrm{C}_{4} ; \delta 3.42$, partly buried under the $\mathrm{H}_{2} \mathrm{O}$ signal, Gly $\mathrm{CH}_{2} ; \delta 8.12$, s (broad), 2.3 (3) $\mathrm{H}$, Gly $\mathrm{NH}_{3} ; \delta 8.30$, d, 0.95 (1) H, ADR NHCO.

\section{GlyLeu-ADR}

GlyLeu-ADR (hydrochloride) was prepared by reaction of Trt-Gly-ONSu and Leu-ADR according to the procedure described for Leu-ADR. Yield $57 \%$, homogeneous on TLC (solvents D, E). ${ }^{1} \mathrm{H}-\mathrm{NMR}$ (DMSO-d $_{6}$ ) consistent with the proposed structure; characteristic signals: $\delta 0.88$, dd, $5.4(6) \mathrm{H}$, Leu $\delta-\mathrm{CH}_{3} ; \delta 1.18, \mathrm{~d}, 2.8$ (3) $\mathrm{H}$, ADR $\mathrm{CH}_{3}-\mathrm{C}_{5} ; \delta 1.45, \mathrm{~m}, 2.8$ (3) $\mathrm{H}$, Leu $\beta-\mathrm{CH}_{2}$ and Leu $\gamma-\mathrm{CH} ; \delta 4.01, \mathrm{~s}, 3.3(3) \mathrm{H}, \mathrm{ADR} \mathrm{CH}_{3} \mathrm{O}-$ $\mathrm{C}_{4} ; \delta 7.9-8.0$, m, 5.4 (6) $\mathrm{H}$, Gly-1 $\mathrm{NH}_{3}$, Leu $\mathrm{NHCO}, \mathrm{ADR} \mathrm{H}-\mathrm{C}_{1}$ and ADR H-C $; \delta 8.46$, d, 0.8 (1) $\mathrm{H}$, ADR NHCO. The Gly $\mathrm{CH}_{2}$ signal is probably buried under the $\mathrm{H}_{2} \mathrm{O}$ signal at $\delta 3.35$.

\section{GlyGlyLeu-ADR}

$N, N$-dicyclohexylcarbodiimide (DCCI) (45.7 $\mathrm{mg}, 0.221 \mathrm{mmol}$ ) was added to a solution of TrtGlyGlyLeu (105 mg, $0.215 \mathrm{mmol}$ ) and $N$-hydroxysuccinimide (HONSu) (24.7 $\mathrm{mg}, 0.215$ $\mathrm{mmol})$ in dichloromethane $(0.8 \mathrm{ml})$ at $0^{\circ} \mathrm{C}$. After $1.5 \mathrm{~h}$ TLC (solvent A) indicated almost complete conversion to the activated ester. The precipitate was filtered off, washed with dichloromethane and the filtrate was evaporated to dryness in vacuo. The residue was dissolved in DMF $(0.8 \mathrm{ml}) . N$-ethylmorpholine $(0.066 \mathrm{ml}$, $0.052 \mathrm{mmol}$ ) and the solution of activated peptide ester $(0.193 \mathrm{ml}, 0.052 \mathrm{mmol})$ were added to a suspension of ADR ( $30.1 \mathrm{mg}, 0.052 \mathrm{mmol}$ ) in DMF $(0.5 \mathrm{ml})$. After a reaction time of $20 \mathrm{~h}$ at room temperature work-up of the mixture and removal of the trityl protecting group as described for Leu-ADR yielded GlyGlyLeu-ADR (hydrochloride) $(36.9 \mathrm{mg}, 79 \%)$. Homogeneous on TLC (solvents D, E). ' H-NMR (DMSO$\mathrm{d}_{6}$ ) consistent with the proposed structure; characteristic signals: $\delta 0.84$, dd, Leu $\delta$ - $\mathrm{CH}_{3} ; \delta 1.14$, d, ADR $\mathrm{CH}_{3}-\mathrm{C}_{5} ; \delta 1.43, \mathrm{~m}$, Leu $\beta-\mathrm{CH}_{2}$ and Leu $\gamma-\mathrm{CH} ; \delta 3.79$, d, Gly-1 or Gly- $2 \mathrm{CH}_{2} ; \delta 4.00$, s, ADR $\mathrm{CH}_{3} \mathrm{O}-\mathrm{C}_{4} ; \delta 4.28$, dd, Leu $\alpha-\mathrm{CH} ; \delta 7.65, \mathrm{~m}$, Leu NHCO and ADR H-C $; \delta 8.06, \mathrm{~d}, \mathrm{ADR}$ NHCO; $\delta 8.50$, t, Gly-2 NHCO.

\section{$P G A$}

PGA was prepared by a procedure [16] which will be reported elsewhere. Briefly, $\gamma$ - (3,4-methylenedioxybenzyl)-L-glutamate ( $\gamma$-piperonyl-Lglutamate, PLG) [15] was converted to the $N$ carboxyanhydride (PLG NCA) which was polymerized in dioxane ( $3 \mathrm{wt} \%$ ) for $160 \mathrm{~h}$ at room temperature using triethylamine (A/I 50) as the initiator yielding poly [ $\gamma$-piperonyl)-L-glutamate ], (PPLG) of $M_{\mathrm{w}} 244,000, \mathrm{DP}_{\mathrm{w}} 927, M_{\mathrm{n}}$ $192,000, \mathrm{DP}_{\mathrm{n}} 729, M_{\mathrm{w}} / M_{\mathrm{n}} 1.27$ as determined by HP-SEC/LALLS. PPLG was deprotected in trifluoroacetic acid/dichloromethane $50 / 50 \mathrm{v} / \mathrm{v}$ containing anisole [16] yielding PGA having a $M_{\mathrm{w}} 73,000\left(\mathrm{DP}_{\mathrm{w}} 565\right)$ as determined by viscometry and a content of residual piperonylester groups of $0.10 \mathrm{~mol} \%$.

\section{$P G A-A D R$}

PGA-ADR was prepared as described earlier [5].

\section{$P G A-G l y G l y-A D R$}

$N, N^{\prime}$-carbonyldiimidazole (CDI) $(436 \mathrm{mg}$, $2.70 \mathrm{mmol}$ ) was added with stirring to a solution of PGA (259.1 mg, $2.01 \mathrm{mmol})$ and saccharinic acid (443 mg, $2.42 \mathrm{mmol}$ ) in DMF $(5.0 \mathrm{ml})$ at room temperature. After $30 \mathrm{~min}$ a solution, prepared by dissolving $\mathrm{HCl}$.GlyGly-OBu ${ }^{\mathrm{t}}$ ( $473 \mathrm{mg}$, $2.11 \mathrm{mmol}$ ) and $N, N, N^{\prime}, N^{\prime}$-tetramethylguanidine (TMG) $(0.265 \mathrm{ml}, 2.11 \mathrm{mmol})$ in DMF $(4.0 \mathrm{ml})$ was added. The reaction mixture was stirred for 4 days at room temperature and was added with stirring to sodium phosphate buffer, pH $7.0(500 \mathrm{ml}, 0.1 \mathrm{M})$. The precipitate was collected by filtration, washed with water (11) and dried in vacuo yielding $\mathrm{PGA}-\mathrm{GlyGly-OBu^{t }}(526$ $\mathrm{mg}, 86 \%$ ). ${ }^{1} \mathrm{H}-\mathrm{NMR}$ (DMSO- ${ }_{6}$ ) was consistent 
with the proposed structure, indicating a spacer load of $92 \mathrm{~mol} \%$.

The brittle product ( $495 \mathrm{mg}$ ) was cut in small pieces which were dissolved with stirring in trifluoroacetic acid (TFA) $(7 \mathrm{ml})$. After $25 \mathrm{~min}$ the solution was evaporated to dryness in vacuo and the residue was dissolved in sodium phosphate buffer, pH $7.4(20 \mathrm{ml}, 0.25 \mathrm{M})$ by addition of $\mathrm{NaHCO}_{3}(7 \%)$ and $\mathrm{NaOH}(1 \mathrm{M})$ to adjust the $\mathrm{pH}$ to 7.4 . The solution was filtered (Whatman GF/A), dialyzed exhaustively against water at $4^{\circ} \mathrm{C}$, filtered $(0.45 \mu \mathrm{m})$ and lyophilized yielding PGA-GlyGly, sodium salt ( $399 \mathrm{mg}, 88 \%$ ). ' $\mathrm{H}-\mathrm{NMR}\left(\mathrm{D}_{2} \mathrm{O}\right)$ was consistent with the proposed structure, indicating a spacer load of $97 \mathrm{~mol} \%$ and a residual content of tertbutyl groups of $0.8 \mathrm{~mol} \%$.

A solution of the polymer $(202 \mathrm{mg})$ in water $(13 \mathrm{ml}$ ) was passed through a column of Dowex $50 \mathrm{~W}$ X-8 $(22 \times 2.6 \mathrm{~cm}$; pyridinium form $)$ using water as the eluent at a flow rate of $35 \mathrm{ml} / \mathrm{h}$. The fractions containing polymer were pooled and lyophilized yielding PGA-GlyGly, pyridinium salt $(185 \mathrm{mg})$. ADR (17.4 mg, $0.0300 \mathrm{mmol}$ ), $N$-ethylmorpholine $(0.0076 \mathrm{ml}, 0.0597 \mathrm{mmol})$ and a solution of EEDQ in DMF $(0.072 \mathrm{ml}$, $0.0360 \mathrm{mmol}$ ) were added to a solution of this carrier $(170 \mathrm{mg}$, ca. $0.63 \mathrm{mmol})$ in DMF $(2.4$ $\mathrm{ml}$ ). The suspension was stirred for 3 days at room temperature in the dark. The red gel product was added to a mixture of sodium phosphate buffer, pH $7.4(32 \mathrm{ml}, 0.25 \mathrm{M})$ and $\mathrm{NaHCO}_{3}$ solution $(0.8 \mathrm{ml}, 7 \%)$ and stirred until dissolution of the gel. The solution was dialyzed exhaustively against water at $4^{\circ} \mathrm{C}$, filtered $(0.45 \mu \mathrm{m})$ and lyophilized. A solution of the conjugate in water $(35 \mathrm{ml})$ was passed through a column of Dowex 50 W X-8 $(26 \times 4.8 \mathrm{~cm}$; sodium form) using water as the eluent at a flow rate of $30 \mathrm{ml} /$ $\mathrm{h}$ and the fractions containing the conjugate were pooled. The solution was filtered $(0.2 \mu \mathrm{m})$ and lyophilized yielding PGA-GlyGly-ADR (121 mg, $55 \%)$.

\section{PGA-GlyGlyGlyLeu-ADR}

PGA-GlyGlyGlyLeu-ADR was prepared as described for PGA-GlyGlyLeu-ADR [5].
Degradation of polymer-bound ADR by lysosomal enzymes

Degradation of polymer-bound ADR conjugates or substrate was studied in a solution containing $0.10 \mathrm{M}$ citric acid, $0.10 \mathrm{M}$ disodium hydrogen phosphate, $1 \mathrm{mM}$ EDTA buffer, adjusted to $\mathrm{pH} 5.50$ with $\mathrm{NaOH}$.

The activity of the thiol enzymes in tritosomes was determined by measuring the increase in UV absorbance at $410 \mathrm{~nm}$ due to release of $p$-nitroaniline using $N^{\alpha}$-benzoyl-Phe-Val-Arg-p-nitroanilide as the substrate according to Subr et al. [24]. Specific activity was $0.025 \Delta A_{410} / \mathrm{min}$ per ml tritosome stock solution.

Tritosomes $(0.72 \mathrm{ml})$ were added to a solution freshly prepared by mixing solutions of polymer-bound ADR $(0.80 \mathrm{ml}, 1 \mathrm{mg} / \mathrm{ml}$ in buffer), reduced glutathione (GSH) $(0.40 \mathrm{ml}$, $25 \mathrm{mM}$ in buffer) and Triton X-100 $(0.24 \mathrm{ml}$, $5 \%$ in water). The mixture was incubated at $37^{\circ} \mathrm{C}$. After specified times a sample $(0.10 \mathrm{ml})$ in a polypropylene tube $(16 \times 100 \mathrm{~mm})$ was mixed with $2 \mathrm{M}$ ammonium formate buffer, $\mathrm{pH}$ $8.50(0.10 \mathrm{ml})$ and water $(0.8 \mathrm{ml})$ [25]. Chloroform/2-propanol $4 / 1 \mathrm{v} / \mathrm{v}(50 \mathrm{ml})$ was added and the mixture was shaken mechanically for 20 min, using a horizontal position of the tube. After centrifugation ( $3000 \mathrm{rpm}, 5 \mathrm{~min}$ ) the aqueous layer was discarded and the organic layer was evaporated under a stream of nitrogen. The residue was dissolved in methanol $(0.10 \mathrm{ml})$ containing daunomycin (DNM) $(1 \mu \mathrm{g} / \mathrm{ml})$ as the internal standard. The solution was analyzed by reversed-phase HPLC.

Assessment of immunogenicity by determining the antibody titres raised against PGA-derived carriers and ADR conjugates

$\mathrm{A} / \mathrm{J}$ female mice (5-8 weeks old) were maintained in a constant environment for 2 weeks. The polymers were made up in Freund's complete adjuvant (FCA) $1: 1 \mathrm{v} / \mathrm{v}$ as a water in oil emulsion and injected $(125 \mu \mathrm{g} /$ mouse $)$ subcutaneously (sc) in mice maintained under halothane anaesthetic ( 5 mice per group). A group of control mice were injected with PBS and the 
vehicle. After 14 days the mice received a second injection (125 $\mu \mathrm{g}$ polymer/mouse) intraperitoneally (i.p.). In this case the polymer $(2 \mathrm{ml}$ of a $1.1 \mathrm{mg} / \mathrm{ml}$ solution) was mixed with $200 \mathrm{ml}$ of $10 \%$ alum neutralized with $1 \mathrm{M} \mathrm{NaOH}$. Fourteen days later this i.p. administration was repeated. The mice were then exsanguinated 7 days later and the blood from each group of mice was pooled and allowed to stand overnight at $4^{\circ} \mathrm{C}$. Sera were removed by aspiration following centrifugation $(1000 \times g, 10 \mathrm{~min})$ which pelleted the erythrocytes and the blood clot. The sera were subsequently stored at $-20^{\circ} \mathrm{C}$ until required for enzyme-linked immunoassay (ELISA).

The IgG and IgM in serum from polymertreated and untreated control animals were determined by the ELISA technique. First the efficiency of antigen binding to the microtiter plates was determined in order to optimize the antigen coating concentration. For ELISA, assay microtiter plates were coated with the polymer at a final concentration of $1 \mathrm{mg} / \mathrm{ml}$ (dissolved in 200 $\mu \mathrm{l}$ PBS and bound overnight at $4^{\circ} \mathrm{C}$ ). The plates were washed three times with $0.05 \%$ Tween 20 in $0.9 \% \mathrm{NaCl}$ in a Titertek plate washer. The sera (in $0.05 \%$ Tween $20 /$ PBS) were serially diluted (2-fold or 10-fold as required) across the plate (final volume $150 \mu \mathrm{l}$ ) and incubated at $37^{\circ} \mathrm{C}$ for $2 \mathrm{~h}$. The initial sera dilutions were $1: 2$ for IgM and $1: 10^{3}$ to $10^{4}$ for IgG. After washing the bound antibody as above, the plate was further incubated $\left(2 \mathrm{~h}\right.$ at $\left.37^{\circ} \mathrm{C}\right)$ with peroxidase-linked goat anti-mouse IgM ( $\mu$-chain specific) or IgG ( $\gamma$-chain specific) each diluted $1: 1000$ in $0.05 \%$ Tween 20/PBS. After further washing, $150 \mu \mathrm{l}$ of the chromophore orthophenylenediamine $(0.04 \%)$ in phosphate-citrate buffer ( $\mathrm{pH} 5.0)$ and peroxidase substrate $\left(0.012 \% \mathrm{H}_{2} \mathrm{O}_{2}\right)$ was added to each well. After $15 \mathrm{~min}$ at room temperature the reaction was stopped with $\mathrm{H}_{2} \mathrm{SO}_{4}$ $(75 \mu \mathrm{l}, 2 \mathrm{M})$ and the absorbance at $492 \mathrm{~nm}$ measured using a Titertek plate reader.

Cytotoxicity of PGA-derived ADR conjugates against i.p. L1210 in mice

Evaluation of ADR and PGA-derived ADR conjugates was carried out essentially as de- scribed in the National Cancer Institute Protocol [26]. DBA 2 mice (males, 9-12 weeks, 20-30 g) were inoculated i.p. at day 0 with $10^{5}$ viable L1210 cells. ADR or polymeric ADR conjugates were administered i.p. at a single dose of $5 \mathrm{mg}$ ADR-equivalents/ $\mathrm{kg}$ at day 1 . For each compound groups of five mice/compound were used. The animals were weighed daily, and observed twice a day for signs of tumor progression. The survival time and the number of long-term survivors (LTS) at day $\mathbf{5 0}$ was monitored.

\section{Results}

\section{Preparation of PGA-derived ADR conjugates}

Two types of polymer-bound ADR conjugates were prepared using the method described previously [5] (Fig. 1, Table 1). In the first type

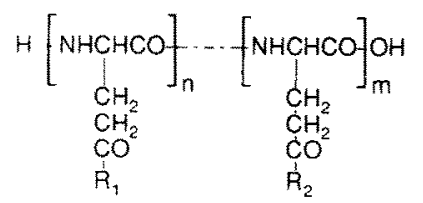

GlyGly $\quad-\mathrm{NHCH}_{2} \mathrm{CONHCH}_{2} \mathrm{COOH}(\mathrm{Na})$

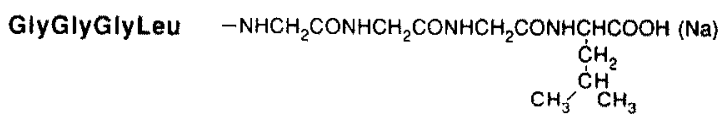

ADR
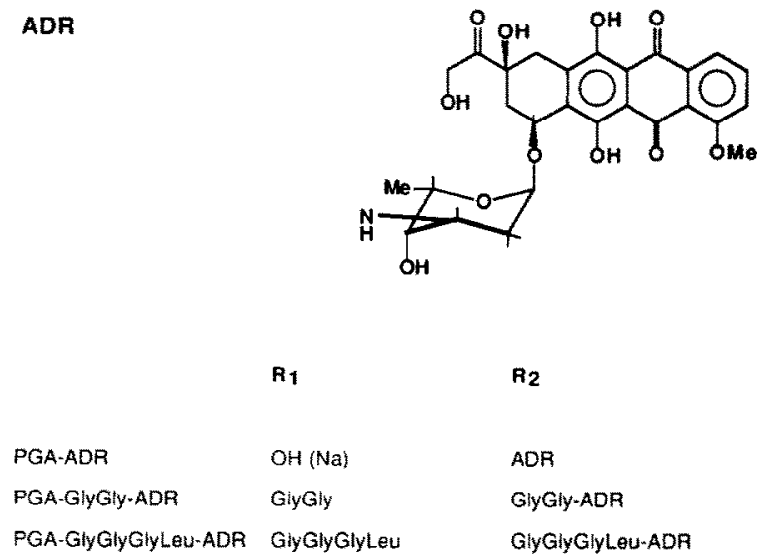

Fig. 1. Conjugates of PGA and ADR. 
TABLE 1

Analytical data of PGA-derived ADR conjugates

\begin{tabular}{|c|c|c|c|c|}
\hline \multirow[t]{2}{*}{ Conjugate } & \multirow{2}{*}{$\begin{array}{l}\text { Molecular } \\
\text { weight }\end{array}$} & \multirow{2}{*}{$\begin{array}{l}\text { Spacer } \\
\text { content }^{\mathrm{b}} \\
(\text { mole } \%)\end{array}$} & \multicolumn{2}{|c|}{ ADR content } \\
\hline & & & wt \% & $\mathrm{mol} \%$ \\
\hline PGA-ADR & 91,000 & - & 8.2 & 2.5 \\
\hline PGA-GlyGly-ADR & 154,000 & 97 & 7.5 & 3.9 \\
\hline PGA-GlyGlyGlyLeu-ADR & 236,000 & 91 & 7.0 & 5.7 \\
\hline
\end{tabular}

Theoretical weight-average molecular weight calculated from $M_{\mathrm{w}}$ of PGA used and the composition as determined by ${ }^{1} \mathrm{H}-\mathrm{NMR}$.

'Relative to Glu.

ADR was linked via the aminoribosyl moiety with part of the carboxyl groups of PGA using EEDQ in DMF yielding the conjugate PGA-ADR with a drug content of $8.2 \mathrm{wt} \%$ as described [5]. For the second type of conjugate PGA was grafted with the oligopeptides GlyGly or GlyGlyGlyLeu. PGA-GlyGlyGlyLeu was obtained by preactivation of the polymer with saccharin and CDI in DMF and subsequent reaction of the saccharin imides with the TMG salt of the oligopeptide as described for PGA-GlyGlyLeu [5]. PGAGlyGlyGlyLeu contains $93 \mathrm{~mol} \%$ of spacer groups relative to Glu residues. Due to the poor solubility of GlyGly in DMF, PGA-GlyGly was prepared by coupling of the C-terminal protected peptide GlyGly-OBut onto PGA preactivated with saccharin and CDI in DMF yielding PGA-GlyGly-OBu ${ }^{t}$ with a $91 \mathrm{~mol}^{\%}$ degree of substitution by spacer groups. The polymerbound tert-butyl ester groups were removed by TFA treatment yielding PGA-GlyGly with $97 \%$ of spacer groups relative to Glu residues.

ADR was coupled to part of the Gly or Leu carboxyl groups of the polymeric carriers using EEDQ in DMF yielding the conjugates PGAGlyGly-ADR or PGA-GlyGlyGlyLeu-ADR with a drug content of 7.5 or $7.0 \mathrm{wt} \%$, respectively.

\section{Preparation of amino acid and peptide derivatives of ADR}

The amino acid and peptide derivatives GlyADR, Leu-ADR, GlyLeu-ADR and GlyGlyLeuADR were prepared by the method of Masquelier et al. [22,27] involving reaction of the
TABLE 2

Analytical data of amino acid and peptide derivatives of ADR

\begin{tabular}{lll}
\hline Compound & $\begin{array}{l}\text { Extraction efficiency } \\
\text { (SD) } \\
(\%)\end{array}$ & $\begin{array}{l}k^{\prime} \\
\text { value }^{\mathrm{b}}\end{array}$ \\
\hline ADR & $57(6.4) ; 54(1.7)^{\mathrm{c}}$ & 3.25 \\
HCl.Gly-ADR & $33(3.4)$ & 3.03 \\
HCl.Leu-ADR & $32(3.8)$ & 5.54 \\
HCl.GlyLeu-ADR & $28(2.6)$ & 7.75 \\
HCl.GlyGlyLeu-ADR & & 8.00 \\
\hline
\end{tabular}

${ }^{a}$ From buffer solution.

${ }^{b}$ In reversed-phase HPLC (see Methods).

'From buffer solution containing tritosomes.

HONSu or HOBT ester of $N$-triphenylmethyl (Trt) protected amino acid or peptide with ADR in DMF (Table 2). The $N$-protected ADR derivatives were purified from minor side products by column chromatography on silica using chloroform/methanol as the eluent and the Trt protecting group was removed by reaction in $75 \%$ acetic acid for $3 \mathrm{~h}$ at room temperature yielding the amino acid or peptide derivatives of ADR as hydrochlorides in overall yields of $39-79 \%$. The final products were found to be homogeneous as judged from reversed-phase HPLC and from ${ }^{1} \mathrm{H}$ NMR. TLC and normal-phase HPLC indicated the presence of trace amounts of aglycone products.

Release of ADR and extractable drug-related compounds from polymeric ADR conjugates by lysosomal enzymes from rat liver

To study the release of drug and drug-related compounds the conjugates PGA-ADR, PGAGlyGly-ADR and PGA-GlyGlyGlyLeu-ADR were incubated with lysosomal enzymes from rat liver (tritosomes) in $0.1 \mathrm{M}$ citric acid/sodium phosphate buffer, $\mathrm{pH} 5.5$, at $37^{\circ} \mathrm{C}$. At specified incubation times up to $77 \mathrm{~h}$ a sample from each incubation mixture was mixed with $1 \mathrm{M}$ ammonium formate buffer, $\mathrm{pH} 8.5$, and extracted with chloroform/2-propanol $4 / 1 \mathrm{v} / \mathrm{v}$. The organic extracts were evaporated to dryness, the residue was dissolved in methanol containing DNM as the internal standard and the solution was ana- 
PGA-ADR

+ tritosomes

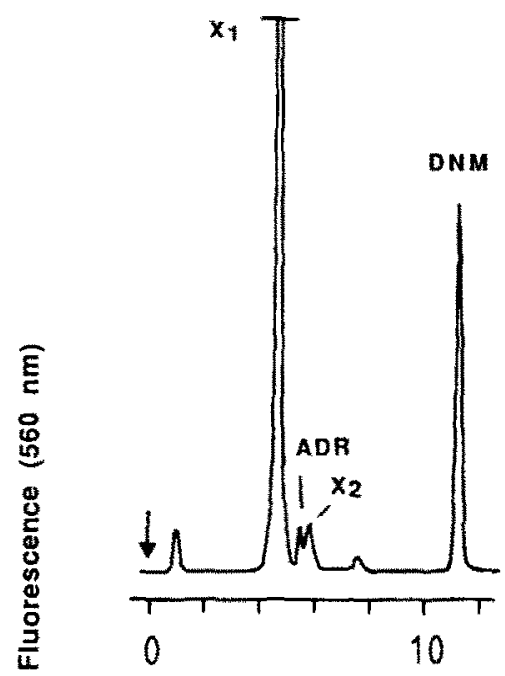

Contral

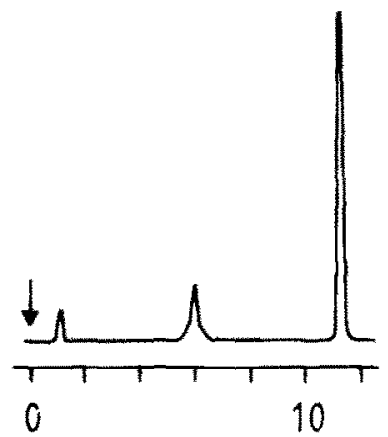

PGA-GIyGIy-ADR

+ tritosomes

PGA-GIyGIyGIyLeU-ADR

+ tritosomes

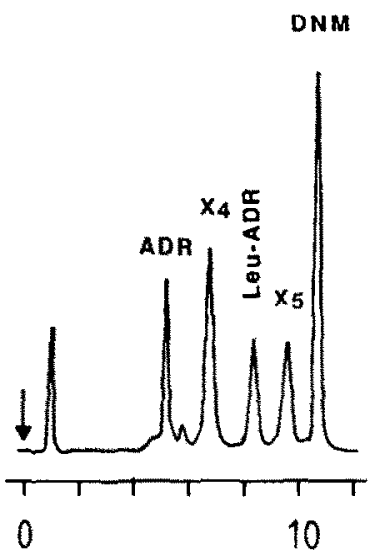

Control

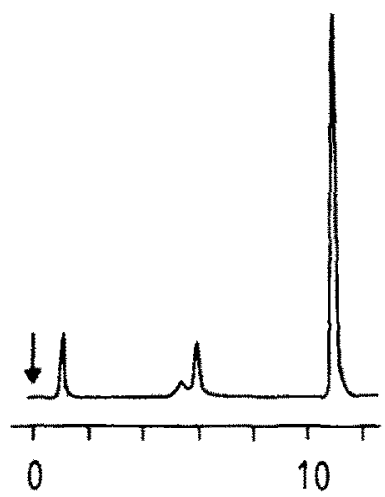

Elution time ( $\mathrm{min})$

Fig. 2. Reversed-phase HPLC analysis of fluorescent extractable products obtained after incubation of PGA-derived ADR conjugates for $46 \mathrm{~h}$ at $37^{\circ} \mathrm{C}$ in the presence or absence of lysosomal enzymes. The incubation mixtures (pH 5.5) contained polymerbound ADR, $0.37 \mathrm{mg} / \mathrm{ml}$ of conjugate; reduced glutathione, $4.6 \mathrm{mM}$; Triton X-100, $0.55 \mathrm{wt} \%$; citric acid, $0.1 \mathrm{M}$; sodium phosphate, $0.1 \mathrm{M} ;$ EDTA, $1 \mathrm{mM}$; lysosomal enzymes (not in controls), $0.17 \mathrm{mg} / \mathrm{ml}$ of protein.

lyzed by reversed-phase HPLC using fluorescence detection of ADR and ADR-related products. The conjugates were also incubated in the absence of enzymes to assess the release of extractable products by non-enzymatic processes. The data were corrected for the loss of compound in the extraction process by using the ex- traction efficiencies determined (Table 2). No corrections were made for the decomposition of ADR and extractable derivatives during the incubation period.

Chromatograms obtained at $46 \mathrm{~h}$ incubation time are shown in Fig. 2. Part of the peaks were assigned by comparison with ADR and the pro- 

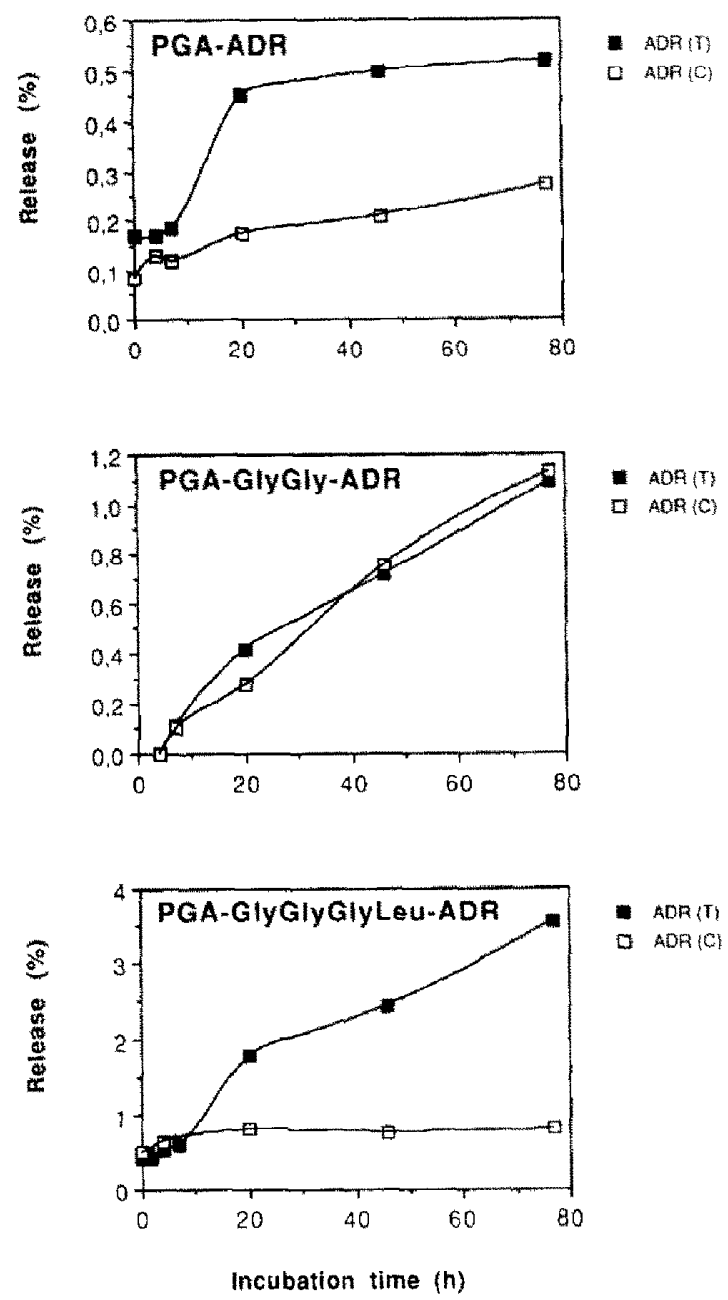

Fig. 3. Time dependence of release of ADR after incubation of PGA-derived ADR conjugates with lysosomal enzymes (T) or in buffer (C),

drugs Gly-ADR, Leu-ADR, GlyLeu-ADR and GlyGlyLeu-ADR (Table 2). The time dependence of the release of ADR or of various assigned products released is plotted in Figs. 3 and 4 , respectively.

In the presence of tritosomes PGA-ADR is degraded to yield one major extractable product $\left(X_{1}\right)$ other than ADR but of unassigned structure. Small amounts of ADR (ca. $0.5 \%$ after 20 h) and another product $\left(X_{2}\right)$ are present. In the control solution without enzymes trace amounts of ADR are present, the increase with time indicating that the polymer-drug bond in the directly
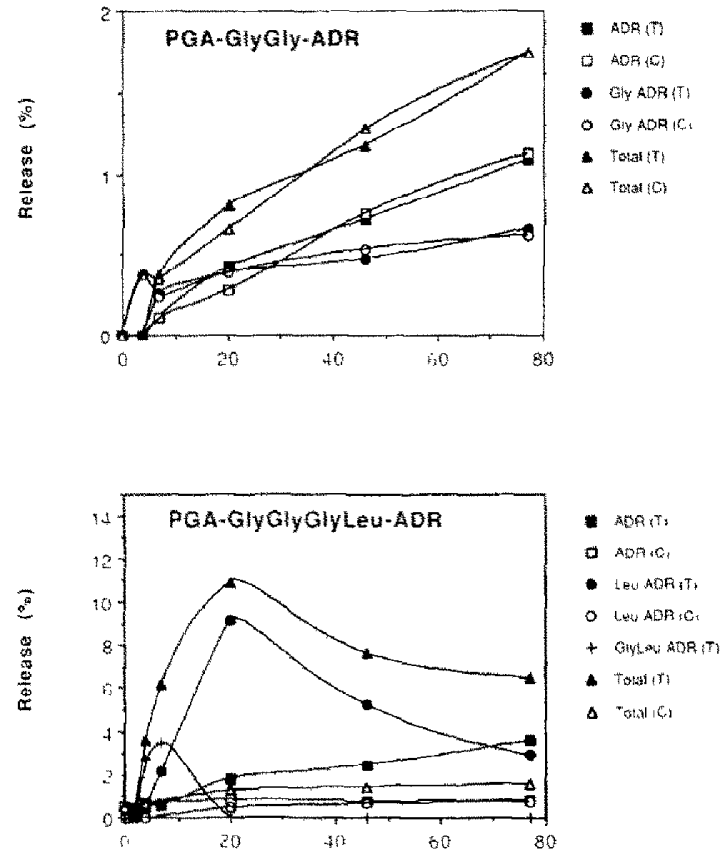

Incubation tume (hy

Fig. 4. Time dependence of release of ADR and ADR derivatives after incubation of PGA-derived ADR conjugates with lysosomal enzymes ( $T$ ) or in buffer $(C)$.

coupled conjugate is very slowly cleaved by chemical hydrolysis. In the presence of tritosomes PGA-GlyGly-ADR yields two products in significant amounts, one of which is assigned to ADR and the other $\left(X_{3}\right)$ is of unknown structure. Trace amounts of Gly-ADR were also observed. The amounts of ADR or Gly-ADR are similar whether tritosomes are present or not, at all time intervals studied, indicating slow chemical hydrolysis of polymer-bound drug. PGAGlyGlyGlyLeu-ADR yields various products in the presence of tritosomes including ADR, LeuADR, GlyLeu-ADR and GlyGlyLeu-ADR as well as unknown compounds $\left(\mathrm{X}_{4}, \mathrm{X}_{5}\right)$ as has been found earlier [7]. The initial release of GlyLeuADR ( $3.5 \%$ at $4 \mathrm{~h}$ ) and Leu-ADR ( $9 \%$ at $20 \mathrm{~h}$ ) is relatively fast, while the release of ADR increases slowly from $0.5 \%$ at $4 \mathrm{~h}$ to $3.5 \%$ at $77 \mathrm{~h}$. Insignificant amounts of GlyGlyLeu-ADR, which practically co-elutes with DNM, were found. The total amount of ADR, Leu-ADR and GlyLeu-ADR present at $20 \mathrm{~h}(11 \%)$ decreases 
on further incubation. This may indicate decomposition of the compounds but this was not further investigated. Small amounts of ADR (0.5$0.8 \%$ ) are released in buffer solution both at the start of the experiment and later on. This can be explained by the presence of ADR as a contaminant in the conjugate preparation and by the occurrence of chemical hydrolysis of polymerbound drug.

\section{Immunogenicity of ADR conjugates}

The drug conjugates PGA-ADR, PGA-GlyGlyADR and PGA-GlyGlyGlyLeu-ADR as well as the carrier polymer PGA-GlyGlyGlyLeu were studied for their ability to induce an antibody response in $\mathrm{A} / \mathrm{J}$ female mice. The materials were administered to groups of 5 mice at a dose of 125 $\mu \mathrm{g} /$ mouse as a $1: 1$ mixture with Freund's complete adjuvant (FCA) on day 0 (sc) and at the same complete dose as an alum precipitate on day 14 (i.p.) and day 28 (i.p.). On day 35 the blood was collected and the titers of immunogen-specific IgG and IgM were determined with horseradish peroxidase-labeled anti-IgG and anti IgM, respectively, by the ELISA technique as described previously [28]. The results are collected in Table 3.

Appreciable titer values $\left(800,000\right.$ units $\left.^{-1}\right)$ were found with PGA-ADR and PGA-GlyGly$A D R$ indicating that these drug conjugates are

TABLE 3

Antibody titers raised against poly ( $\alpha$-L-glutamic acid) and adriamycin derivatives after repeated administration to $\mathrm{A} / \mathrm{J}$ female mice $(n=5)$ in Freund's complete adjuvant and alum ${ }^{2}$

\begin{tabular}{lll}
\hline Compound & \multicolumn{2}{l}{ Titer $^{-1}$} \\
\cline { 2 - 3 } & IgG & IgM \\
\hline Control (PBS+FCA) & $0(0)$ & $0.02(0.01)$ \\
PGA-GlyGlyGlyLeu & $0(0)$ & $0.07(0.03)$ \\
PGA-ADR & $8.14(1.63) \times 10^{5}$ & $0.05(0.02)$ \\
PGA-GlyGly-ADR & $8.14(1.63) \times 10^{5}$ & $0.03(0.02)$ \\
PGA-GlyGlyGlyLeu-ADR & $0.04(0.02)$ & $0.03(0.02)$ \\
\hline
\end{tabular}

Titres for $\operatorname{IgG}$ and $\mathrm{IgM}$ are mean values $( \pm S E)$ of three separate ELISA assays.

${ }^{B}$ Animals showed signs of ADR toxicity. immunogenic. The titer values are lower in magnitude by $2-3$ orders of ten compared with the titer found after administration of the strong immunogen bovine IgG to A/J mice [28] and the ADR conjugates may thus be classified as moderately strong immunogens. In contrast, the drug conjugate PGA-GlyGlyGlyLeu-ADR generates a very low level of antibodies (titer value 0.04 ) while no antibodies were detected with the carrier polymer PGA-GlyGlyGlyLeu. For all materials the level of IgM antibodies at day 35 is low (titer values $0.02-0.07$ ) in agreement with the usual time dependence of the IgM response to immunogens.

\section{In vivo cytotoxicity of $A D R$ conjugates}

PGA-ADR, PGA-GlyGly-ADR and PGAGlyGlyGlyLeu-ADR were compared for their capability to suppress the growth of L1210 cells implanted intraperitoneally in $\mathrm{DBA}_{2}$ mice. $\mathrm{A}$ single dose ( $5 \mathrm{mg}$ ADR-equivalents $/ \mathrm{kg}$ ) of each polymeric ADR conjugate as well as free ADR was administered i.p. on day 1 using groups of 5 mice and the survival time, the mean body weight and the LTS were monitored. The results are given in Table 4 and Figs. 5 and 6, respectively.

Untreated animals show a steady increase in body weight for 9-10 days after tumor inoculation due to tumor growth and die at 12.6 days. A single dose of free ADR administered on day 1 suppresses the tumor growth significantly up to day $12-13$ as shown by the reduced increase of the body weight, the enhanced value of the MST

TABLE 4

Effect of i.p. adminustration of PGA-ADR conjugates on $\mathrm{DBA}_{2}$ mice $\left(n=5\right.$ ) bearing $10^{5} \mathrm{~L} 1210$ cells inoculated i.p. on day 0 (dose $5 \mathrm{mg}$ ADR/ $\mathrm{kg}$ on day $\mathrm{l}$ )

\begin{tabular}{llllll}
\hline Compound & $\begin{array}{l}\text { Survival } \\
\text { time } \\
\text { (days) }\end{array}$ & $\begin{array}{l}\text { MST } \\
\text { (SE) }\end{array}$ & $\begin{array}{l}\text { T/C } \\
\text { (days) }\end{array}$ & $\begin{array}{l}\text { LTS } \\
\text { (day }\end{array}$ \\
\hline Controls & $11,13,13,13,13$ & $12.6(0.4)$ & - & $0 / 5$ \\
ADR & $15,16,21,22$ & $18.5(1.8)$ & 147 & $1 / 5$ \\
PGA-ADR & $14,14,14,14,14$ & $14.0(0)$ & 111 & $0 / 5$ \\
PGA-GlyGly-ADR & $14,14,18,24,24$ & $18.8(2.2)$ & 149 & $0 / 5$ \\
PGA-GlyGlyGlyLeu-ADR & $15,17,24$ & $18.7(2.7)$ & 148 & $2 / 5$ \\
\hline
\end{tabular}




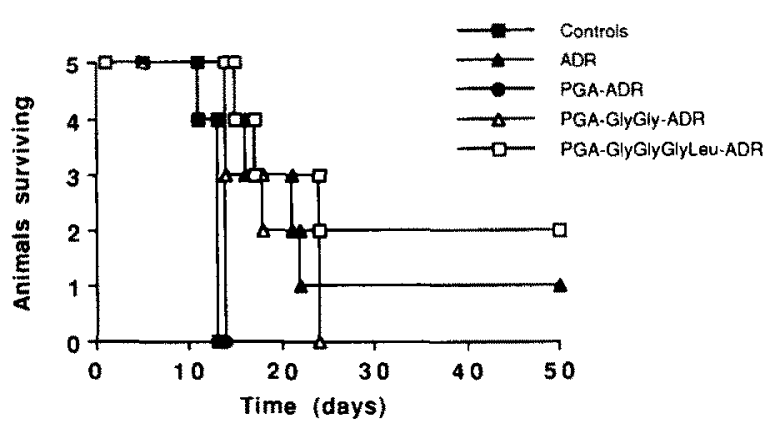

Fig. 5. Effect of treatment of $D B A_{2}$ mice carrying i.p. L1210 with $A D R$ or $P G A$-derived $A D R$ conjugates on survival.

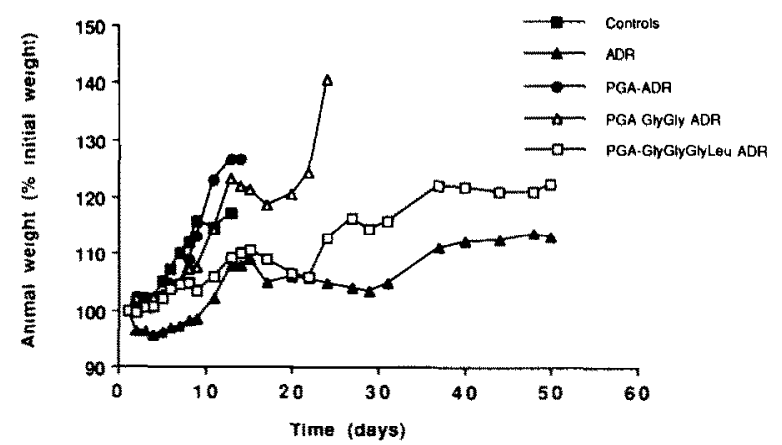

Fig. 6. Effect of treatment of $\mathrm{DBA}_{2}$ mice carrying i.p. $\mathrm{L} 1210$ with ADR or PGA-derived ADR conjugates on body weight.

(18.5 days) and the presence of LTS at day 50 $(1 / 5)$. Animals treated with PGA-ADR at day 1 show an increase in body weight and MST (14.0 days) very similar to the data of the untreated control group indicating that this conjugate is therapeutically ineffective. PGA-GlyGly-ADR does not suppress the initial tumor growth as shown by the increase in body weight during the first period of 12-13 days. After day 12-13 a decline in body weight is seen. Consistently, the MST of animals treated with PGA-GlyGly-ADR (18.8 days) is larger than that of the control group (12.6 days) indicating a definite therapeutic effect comparable to free ADR although no LTS at day 50 were observed. The body weight of animals treated with PGA-GlyGlyGlyLeuADR shows a modest increase up to day 12-13 followed by a decrease up to day 24 and an increase thereafter. The MST of 18.7 days is similar to that found for PGA-GlyGly-ADR or ADR and 2 out of 5 animals survive at day 50 . These data indicate that PGA-GlyGlyGlyLeu-ADR is a therapeutically active conjugate. Qualitatively, the order of ADR conjugates with respect to in vivo antitumor action is PGA-GlyGlyGlyLeuADR $\geq A D R>$ PGA-GlyGly-ADR $\gg$ PGA-ADR.

\section{Discussion}

\section{Release of ADR from polymeric conjugates}

The release of ADR and the release as well as the nature of extractable ADR derivatives mediated by lysosomal enzymes acting on PGAADR, PGA-GlyGly-ADR and PGA-GlyGlyGlyLeu-ADR is obviously strongly affected by the conjugate structure, especially the presence and composition of a peptide spacer between drug and carrier. PGA-GlyGlyGlyLeu-ADR is degraded to an appreciable extent yielding drug and low-molecular weight drug-spacer fragments, notably GlyLeu-ADR and Leu-ADR. The enzymatic degradation is probably mediated by the endopeptidase action of lysosomal proteinases such as cathepsin B, L (both thiol-dependent) and $D$ in combination with the exopeptidase action of lysosomal dipeptidases, including the thiol-dependent cathepsin C, and aminopeptidases, including the thiol-dependent cathepsin $H[29,30]$. The presence of the drug derivatives GlyLeu-ADR and Leu-ADR in addition to ADR indicates that the GlyGlyGlyLeu spacer provided a rather low specificity in the lysosomal degradation. On the other hand, spacers yielding highly specific tritosome-mediated ADR release from polymeric conjugates contain two or more hydrophobic amino acids which, when grafted onto PGA, would yield a rather hydrophobic carrier. In turn, substitution of such a hydrophobic carrier by the very hydrophobic ADR moiety probably results in strong associative phenomena or insolubility. Thus, the GlyGlyGlyLeu spacer provides a compromise between solubility of the drug conjugate and lysosomal degradability of the drug-carrier linkage. PGA-GlyGlyADR yields trace amounts of ADR increasing 
with time either in the presence or absence of tritosomes. This indicates that slow chemical hydrolysis of the drug-polymer bond occurs presumably due to a catalytic effect of neighbouring polymer-bound carboxyl groups or of buffer components. Apparently, one product of as yet unassigned structure is produced from PGAGlyGly-ADR by the action of lysosomal enzymes. The absence of any ADR release from PGA-GlyGly-ADR attributable to the action of lysosomal enzymes agrees with earlier data on polyHPMA conjugates of GlyGly-DNM showing complete stability of the polymer-bound drug towards tritosomes [31 ]. Trace amounts of ADR are also produced from PGA-ADR conjugates either in the presence or absence of tritosomes apparently due to chemical hydrolysis of the polymer-bound drug. Tritosomes effect the release of one product from PGA-ADR in significant amounts but its structure is as yet unknown.

In summary, the rate of ADR release from polymeric conjugates mediated by tritosomes can be regulated by the use of an enzymatically cleavable spacer. Chemical hydrolysis of the drug-polymer bond is also observed but seems of minor importance.

\section{Immunogenicity of ADR conjugates}

In order to be therapeutically effective, polymer-bound cytostatics should remain in the circulation for prolonged time periods. When conjugates are immunogenic, rapid capture by macrophages or inflammatory reactions may occur especially after repeated administration by which the immune response is enhanced. These events are generally undesirable although capture by and degradation in macrophages may contribute to cytotoxicity towards target cells in some cases.

PGA-derived ADR conjugates were administered using sustained-release dosage forms with FCA and alum, which also stimulate the immune system. These conditions are a strong challenge for the immune system. The immune response obtained may not always be representative for therapeutic administration. A moderate dose was given threefold with a fre- quency of 14 days to reduce the possible contribution of immunologic paralysis [28]. The magnitude of the secondary ( $\mathrm{IgG}$ ) antibody response elicited by PGA-derived drug conjugates in $\mathrm{A} / \mathrm{J}$ mice at day 35 is clearly dependent on the chemical structure of the conjugates (Table 3). Extensive studies have been performed on the immunological properties of poly ( $\alpha$-L-amino acids), vinyl polymers and natural macromolecules including dextrans and proteins as well as carrierbound haptens such as chromophores, drugs and nucleotides [32-35]. From these studies general rules governing immunogenicity of materials have been deduced. Homopolymers including PGA generally show no or only a weak immunogenicity which has been explained by the flexibility of the polymers in aqueous solution and the homogeneous surface due to the repeating nature of the chemical structure. When the primary structure of the macromolecule is more complicated such as in block and graft copolymers or polymers carrying haptens, various parts of rather small molecular dimensions on the macromolecule (epitopes) may induce the formation of complementary antibodies presumably due to the heterogeneity of the surface. Notably, ADR bound to BSA has been found to be immunogenic and monoclonal antibodies directed against different parts of the ADR moiety have been isolated indicating that ADR can act as a hapten [36]. Thus, the immunogenicity of PGAADR and PGA-GlyGly-ADR might be well due to the drug moiety. Although PGA has been found previously to be non-immunogenic, the monomer units may become immunogenic in the PGA-ADR conjugate as found previously for HPMA copolymers [28]. The immunogenicity of the PGA-GlyGly-ADR conjugate may be due to the glutamine backbone units, the drug as already mentioned, or to the spacer which has been found previously to act as an epitope when bound to polyHPMA [28]. The absence of immunogenicity of PGA-GlyGlyGlyLeu and the ADR conjugate suggests that neither the carrier, spacer nor drug acts as an epitope. Due to the method of antibody detection used in the present study, the absence of immunogenicity of PGA-GlyGly- 
GlyLeu-ADR might theoretically be due to cytotoxic effects of free ADR after degradation of the conjugate prior to presentation to immunocompetent cells. A very low antibody response to conjugate of ADR bound through a biodegradable GlyPheLeuGly spacer to polyHPMA has been found previously [37]. The viability of the immunocompetent cells was found unimpaired as measured by the antibody response against sheep red blood cells simultaneously administered with ADR conjugate. Nevertheless, a more detailed study on the effect of PGA-derived conjugates on the state of the immune system seems warranted in view of the different conjugate structure and the use of adjuvant in our case.

\section{Cytotoxicity of ADR conjugates}

The in vivo efficacy of PGA-derived ADR conjugates against L1210 tumour cells is dependent on the chemical structure. PGA-ADR is totally ineffective. PGA-GlyGlyGlyLeu-ADR and PGA-GlyGly-ADR enhance the mean survival time of treated animals significantly relative to the untreated control group. The GlyGlyGlyLeu-containing conjugate is the most effective as shown by the presence of long-term survivors at day 50 which was observed for free ADR as well but not with the GlyGly-containing conjugate. The cytotoxic efficacy of the PGAGlyGlyGlyLeu-ADR is consistent with the relatively fast rate of tritosomes-mediated release of ADR pointing to in vivo release of free drug in lysosomal compartments. However, the cytotoxic effectivity of the GlyGly and GlyGlyGlyLeu conjugates does not surpass that of free ADR on the basis of total drug administered. In this study a single dose of each of the conjugates was administered and repeated dosage would be expected to enhance the cytotoxicity. For a more definite assessment of the therapeutic potential of the PGA-bound conjugates studies on pharmacodynamics and on drug-related side effects, notably cardiotoxicity, will be needed.

It has been found in previous studies that the growth of L1210 cells in vitro by PGA-derived ADR conjugates having GlyGlyLeu and GlyGlyGlyLeu spacers was inhibited only at high doses of conjugates $[6,7]$. This was tentatively explained by inefficient uptake by and/or degradation in the cells $[6,7]$. Thus, the significant in vivo antitumor activity of GlyGlyGlyLeucontaining ADR conjugate against $\mathrm{L} 1210$ cells found in the present study is not anticipated from the in vitro data. In our recent study on the biodistribution of immunoconjugates of PGA and PHEG after i.v. administration to mice a high uptake of free PGA in liver and a very low level in blood was found [13]. The RES targeting of PGA may be well due to the anionic charge of the polymer similar to other polyanions [38]. On this basis the ADR conjugates when administered i.p. might be taken up efficiently by peritoneal macrophages, in which then lysosomal degradation can occur, and free ADR may diffuse out of the macrophages. Thus the fate and processing of ADR conjugates may be similar to that of i.p. administered ADR-containing liposomes [39].

The high cytotoxic effectivity of the PGAGlyGly-ADR conjugate is not expected in view of the very low rate of ADR release observed in solution either in the presence or absence of tritosomes. At present we speculate that the cytotoxicity of PGA-GlyGly-ADR conjugate might be due to mechanisms other than those effected by free drug. For instance, the polymer-bound drug might mediate cytotoxic effects by interaction with the target cell membrane as has been proposed earlier to explain the in vitro cytotoxicity of polyHPMA carrying DNM bound to the nondegradable GlyGly spacer [40]. This effect was not noticeable in vivo for conjugates of polyHPMA and GlyGly-DNM or GlyGly-ADR, which were found totally inactive $[3,41]$, thus contrasting with the present results. On the basis of the immunogenic nature of the PGA-GlyGlyADR conjugate we include the possibility that biological defense mechanisms are activated.

\section{Conclusions}

PGA-GlyGlyGlyLeu-ADR conjugate having a lysosomally cleavable spacer enhances the sur- 
vival time of mice carrying i.p. L1210 tumor cells after a single i.p. dose of conjugate.

The cytotoxicity of this conjugate is probably due to release of ADR mediated by lysosomal enzymes and may well occur in RES cells.

The antitumor activity of PGA-GlyGly-ADR has to be explained by mechanisms not yet established.

\section{Acknowledgements}

This work has been supported by the Netherlands Organization for Scientific Research (NWO). Thanks are due to Farmitalia (Milan, Italy) for providing adriamycin.

\section{References}

1 C.J.T. Hoes and J. Feijen, The application of drug-polymer conjugates in chemotherapy, in: F.H.D. Roerdink and A.M. Kroon, (Eds.), Drug-Carrier Systems, Wiley and Sons Ltd, Chichester, U.K., (1989), pp. 57-109.

2 R. Duncan and J. Kopecek, Soluble synthetic polymers as potential drug carriers, Adv. Polymer Sci. 57, (1984) 57-101.

3 R. Duncan, I.C. Hume, P. Kopeckova, K. Ulbrich, J. Strohalm and J. Kopecek, Anticancer agents coupled to $\mathrm{N}$-(2hydroxypropyl)methacrylamide copolymers. 3. Evaluation of adriamycin conjugates against mouse leukaemia L1210 in vivo, J. Controlled Release 10, (1989) 51-63.

4 C.E. Myers, Anthracyclines, in: B. Chabner (Ed.), Pharmacologic Principles of Cancer Treatment 1982, pp. 416-434.

5 W.A.R. van Heeswijk, C.J.T. Hoes, T. Stoffer, M.J.D. Eenink, W. Potman and J. Feijen, The synthesis and characterization of polypeptide-adriamycin conjugates and its complexes with adriamycin. Part I., J. Controlled Release 1, (1985) 301-315.

6 C.J.T. Hoes, W. Potman, W.A.R. van Heeswijk, J. Mud, B.G. de Grooth, J. Greve and J. Feijen, Optimization of macromolecular prodrugs of the antitumor antibiotic adriamycin, J. Controlled Release 2, (1986) 205-213.

7 C.J.T. Hoes, W. Potman, B.G. de Grooth, J. Greve and J. Feijen, Chemical control of drug delivery, in: A.F. Harms (Ed.), Innovative Approaches in Drug Research Elsevier Science Publ., (1986), pp. 267-283.

8 P.H. Maurer, Attempts to produce antibodies to a preparation of polyglutamic acid, Proc. Soc. Exp. Biol. Med. 96, (1957) 394-396.

9 A.D. Kenny, Evaluation of sodium poly- $\alpha$, L-glutamate as a plasma expander, Proc. Exp. Biol. Med. 100, (1959) 778-780.
10 A. Kato, Y. Takakura, M. Hashida, T. Kimura and H. Sezaki, Physicochemical and antitumor characteristics of high molecular weight prodrugs of mitomycin C, Chem. Pharm. Bull. 30, (1982) 2951-2957.

11 C.F. Roos, S. Matsumoto, Y. Takakura, M. Hashida and H. Sezaki, Physicochemical and antitumor characteristics of some polyamino acid prodrugs of mitomycin C, Int. J. Pharm. 22, (1984) 75-87.

12 Y. Kato, M. Saito, H. Fukushima, Y. Takeda and T. Hara, Antitumor activity of 1- $\beta$-D-arabinofuranosylcytosine conjugated with polyglutamic acid and its derivative, Cancer Res. 44, (1984) 25-30.

13 C.J.T. Hoes, J. Grootoonk, J. Feijen, P.J. Boon, F. Kaspersen, P. Loeffen, I. Schlachter, M. Winters and E.S. Bos, Synthesis and biodistribution of immunoconju* gates of a human IgM and polymeric drug carriers, J. Controlled Release 19 (1992) 59-76.

14 A.T. Moore, H.N. Rydon and M.J. Smithers, Polypeptides. Pan XIV. The synthesis of some oligopeptides containing lysine and glutamic acid residues, J. Chem. Soc. (C), (1966) 2349-2359.

15 W.A.R. van Heeswijk, M.J.D. Eenink and J. Feijen, An improved method for the preparation of $\gamma$-esters of glutamic acid and $\beta$-esters of aspartic acid, Synthesis 9 (1982) 744-747.

16 M.J.D. Eenink, Synthesis of biodegradable polymers and development of biodegradable hollow fibers for the controlled release of drugs, Ph.D. thesis, University of Twente, 1987.

17 G.W. Anderson, J.E. Zimmerman and F. Callahan, The use of esters of $\mathrm{N}$-hydroxysuccinimide in peptide synthesis, J. Am. Chem. Soc. 86 (1964) 1839-1842.

18 K. Barlos, D. Papaioannou and D. Theodoropoulos, Preparation and properties of $\mathrm{N}^{\alpha}$-trityl amino acid 1hydroxybenzotriazole esters, Int. J. Peptide Protein Res. 23, (1984) 300-305.

19 A. Trouet, Isolation of modified liver lysosomes, Methods Enzymol. 31 (1974) 323-329.

20 K.D. Kussendrager, Y. de Jong, J.M.W. Bouma and M. Gruber, The digestion of the B-chain of oxidized insulin by extracts of rat liver lysosomes, Biochim. Biophys. Acta 279 (1972) 75-86.

21 F. Reindel and W. Hoppe, Utber eine Färbemethode zum Anfärben von Aminosauren, Peptiden und Proteinen auf Papierchromatogrammen und Papierelektropherogrammen, Chem. Ber. 87 (1954) 1103-1107.

$22 \mathrm{M}$. Morcellet and C. Loucheux, Viscosity/molecularweight relationship of poly ( $\alpha$-L-glutamic acid in water and in water/dioxane mixtures, Biopolymers 15, (1976) 1857-1862.

23 M. Masquelier, Couplage covalent réversible de la daunorubicine et de la primaquine à des protéines: application à une chimiothérapie plus selective du cancer et de la malaria, $P h, D$. thesis, University of Leuven, 1981.

24 V. Subr, J. Kopecek and R. Duncan, Degradation of oligopeptide sequences connecting poly[N-(2-hydroxypropyl)methacrylamide] chains by lysosomal cysteine 
proteinases, J. Bioact. Comp. Polymers 1 (1986) 133146.

25 M.A. van Lancker, L.A. Bellemans and A.P. de Leenheer, Quantitative determination of low concentrations of adriamycin in plasma and cell cultures, using a volatile extraction buffer, J. Chromatogr. 374 (1986) 415420.

26 R.I. Geran, N.H. Greenberg, M.M. McDonald, A.M. Schumacher and B.J. Abbott, Protocols for screening chemical agents and natural products against animal tumours and other biological systems, Cancer Chemother. Rep. 3 (1972) 1.

27 M. Masquelier, R. Baurain and A. Trouet, Amino acid and dipeptide derivatives of daunorubicin. 1. Synthesis, physicochemical properties, and lysosomal digestion, J. Mcd. Chem. 23 (1980) 1166-1170.

28 B. Rihova, J. Kopecek, K. Ulbrich, M. Pospisil and P. Mancal, Effect of the chemical structure of N-(2-hydroxypropyl ) methacrylamide copolymers on their ability to induce antibody formation in inbred strains of mice, Biomaterials 5 (1984) 143-148.

29 R. Duncan, H.C. Cable, J.B. Lloyd, P. Rejmanova and J. Kopecek, Design of oligopeptide side-chains in poly [N-(2-hydroxypropyl)methacrylamide] copolymers to promote efficient degradation by lysosomal enzymes, Makromol. Chem. 184 (1983) 1997-2008.

30 V. Subr, J. Kopecek, J. Pohl, M. Baudys and V. Kostka, Cleavage of oligopeptide side-chains in $\mathrm{N}$-(2-hydroxypropyl)methacrylamide copolymers by mixtures of lysosomal enzymes, J. Controlled Release 8 (1988) 133140.

31 J. Kopecek and R. Duncan, Poly N-(2-hydroxypropyl)methacrylamide macromolecules as drug carrier systems, in: L. Illum and S.S. Davis (Eds.), Controlled release of Drugs from Polymeric Particles and Macromolecules, Adam Hilger, Bristol, U.K., 1987, pp. 152170.

32 M. Sela, Immunological studies with synthetic polypeptides, Adv. Immunol. 5 ( 1966) 29-129.
33 M. Sela, Antigenicity: some molecular aspects. Science 166 (1969) 1365-1374.

34 B. Rihova and I. Riha, Immunological problems of polymer-bound drugs, in: CRC Critical Reviews in Therapeutic Drug Carrier systems, Vol. 1, 1985, pp. 311374.

35 M.H.V. van Regenmortel, Molecular dissection of protein antigens and the prediction of epitopes, in: M.H.V. van Regenmortel, J.P. Briand, S. Muller and S. Plaué (Eds), Synthetic Polypeptides as Antigens, Elsevier Publ. Co., Amsterdam, 1988, ch. 1, pp. 1-40.

36 A. Balsari, M.I. Colnaghi and M. Ghione, Monoclonal antibodies to anthracyclines. Eur. Patent Appl. no. 88118771.0 (1988); Chemical Abstracts 112, 5950a.

37 B. Rihova, M. Bilej, V. Vetvicka, K. Ulbrich, J. Strohalm, J. Kopecek and R. Duncan, Biocompatibility of $\mathrm{N}$-(2-hydroxypropyl)methacrylamide copolymers containing adriamycin, Biomaterials 10 (1989) 335-342.

38 R.M. Ottenbrite, Bioactive carboxylic acid polyanions, in: C.G. Gebelein and C.E. Carrahar (Eds), Bioactive Polymeric Systems Plenum Press, New York, 1985, pp. 513-529.

39 G. Storm, Liposomes as delivery system for doxorubicin in cancer chemotherapy, Ph.D. Thesis, University of Utrecht, 1987.

40 R. Duncan, P. Kopeckova-Rejmanova, J. Strohalm, I. Hume, H.C. Cable, J. Pohl, J.B. Lloyd and J. Kopecek, Anticancer agents coupled to N-(2-hydroxypropyl)methacrylamide copolymers. I. Evaluation of daunomycin and puromycin conjugates in vitro, $\mathrm{Br}$. J. Cancer 55 (1987) 165-174.

41 R. Duncan, P. Kopeckova, J. Strohalm, I.C. Hume, J.B. Lloyd and J. Kopecek, Anticancer agents coupled to N(2-hydroxypropyl)methacrylamide copolymers. II. Evaluation of daunomycin conjugates in vivo against L1210 leukaemia, Br. J. Cancer 57 (1988) 147-156. 